\title{
The influence of charge stratification on the spectral signature of partially premixed combustion in a light-duty optical engine
}

\author{
M. Izadi Najafabadi ${ }^{1} \cdot$ Luc Egelmeers $^{1} \cdot$ Bart Somers $^{1} \cdot$ Niels Deen $^{1} \cdot$ \\ Bengt Johansson ${ }^{2} \cdot$ Nico Dam ${ }^{1}$
}

Received: 29 August 2016 / Accepted: 28 February 2017 / Published online: 25 March 2017

(c) The Author(s) 2017. This article is an open access publication

\begin{abstract}
The origin of light emission during low-temperature combustion in a light-duty IC engine is investigated by high-speed spectroscopy in both HCCI and PPC regimes. Chemiluminescence and thermal radiation are expected to be the dominant sources of light emission during combustion. A method has been developed to distinguish chemiluminescence from thermal radiation, and different chemiluminescing species could be identified. Different combustion modes and global equivalence ratios are analyzed in this manner. The results indicate that the spectral signature (270-540 $\mathrm{nm}$ range) of the combustion is highly dependent on the stratification level. A significant broadband chemiluminescence signal is detected and superimposed on all spectra. This broadband chemiluminescence signal can reach up to 100 percent of the total signal in HCCI combustion, while it drops to around 80 percent for stratified combustion (PPC). We show that this broadband signal can be used as a measure for the heat release rate. The broadband chemiluminescence did also correlate with the equivalence ratio quite well in both HCCI and PPC regimes, suggesting that the total emission in the spectral region of 330-400 $\mathrm{nm}$ can serve as a proxy of equivalence ratio and the rate of heat release. Regarding $\mathrm{C}_{2} *$ chemiluminescence, we see two different chemical mechanisms for formation of $\mathrm{C}_{2}{ }^{*}$ in the PPC regime: first during the early stage of combustion by the breakup of bigger molecules
\end{abstract}

M. Izadi Najafabadi

M.Izadi.Najafabadi@tue.nl

1 Multiphase and Reactive Flows Group, Department of Mechanical Engineering, Eindhoven University of Technology, P.O. Box 513, 5600 MB Eindhoven, The Netherlands

2 Clean Combustion Research Center, King Abdullah University of Science and Technology, Thuwal, Saudi Arabia and the second during the late stage of combustion when soot particles are forming.

Keywords Spectroscopy · PPC - Chemiluminescence · Thermal radiation $\cdot$ IC Engine

\begin{tabular}{|c|c|}
\hline \multicolumn{2}{|c|}{ Abbreviations } \\
\hline ATDC & After top dead center \\
\hline CA50 & Crank angle at $50 \%$ burn \\
\hline CAD & Crank angle degree \\
\hline $\mathrm{CI}$ & Compression ignition \\
\hline CMOS & Complementary metal-oxide semiconductor \\
\hline fps & Frames per second \\
\hline HCCI & Homogeneous charge compression ignition \\
\hline IC & Internal combustion \\
\hline ID & Ignition delay \\
\hline $\mathrm{C}_{2} *$ & Electronically excited dicarbon \\
\hline $\mathrm{CH}^{*}$ & Electronically excited methylidyne \\
\hline $\mathrm{CH}_{2} \mathrm{O} *$ & Electronically excited formaldehyde \\
\hline $\mathrm{CO}_{2} *$ & Electronically excited carbon dioxide \\
\hline $\mathrm{OH}^{*}$ & Electronically excited hydroxyl \\
\hline $\mathrm{HCO} *$ & Electronically excited formyl \\
\hline PPC & Partially premixed combustion \\
\hline PRFnn & $\begin{array}{l}\text { Primary reference fuel, } \mathrm{nn}=\text { the percentage of } \\
\text { iso-octane in iso-octane } / n \text {-heptane mixture }\end{array}$ \\
\hline rpm & Revolutions per minute \\
\hline SCCI & Stratified charge compression ignition \\
\hline SI & Spark ignition \\
\hline SOI & Start of injection \\
\hline
\end{tabular}

\section{Introduction}

Partially premixed combustion (PPC), a combustion mode of compression-ignition (CI) internal combustion (IC) 
engines, relies on a relatively long ignition delay (ID) to achieve a partially premixed charge [1-6]. PPC is a promising combustion concept allowing to reduce both $\mathrm{NO}_{\mathrm{x}}$ and soot emissions while providing high combustion efficiency. By and large, the low $\mathrm{NO}_{\mathrm{x}}$ emissions result from the low combustion temperature, whereas the low soot emission is a result of increased premixing (with respect to conventional CI engines) [2-6]. However, many details of the incylinder phenomena are still to be explained and evaluated.

By coupling a high-speed camera to a spectrograph, crank-angle- and cycle-resolved spectroscopic data, containing detailed information regarding the species formation during the combustion, can be obtained. Chemiluminescence and thermal radiation are expected to be the dominant sources of luminescence during the combustion [7]. Depending on the combustion mode, the intensity of these two contributions will vary. Thermal radiation is mainly composed of black-body radiation coming from soot particles that are heated to flame temperatures by the combustion process [8], while the term chemiluminescence is used for the light emission of specific molecules, which are formed in an electronically excited state during combustion and spontaneously decay back to lower energy levels $[8,9]$. Chemiluminescence occurs in specific wavelength bands that are characteristic of the emitting molecules. The chemiluminescence yield due to specific molecules varies for different combustion regimes, and this can provide information about the nature of the chemistry involved [9-11]. Because chemiluminescence is the direct product of exothermic chemical reactions, it marks the location of the initial combustion reactions, both temporally and spatially [10], although reaction pathways leading to chemiluminescent species are under debate [12]. In practical implementation, a drawback is that the collected light is integrated along the line of sight of the detector. By any means, chemiluminescence imaging is a useful tool for time- and space-resolved investigation of the reactions that occur during combustion [13].

Molecular spectroscopy has also been used to study HCCI combustion in IC engines. Hultqvist et al. [9] obtained chemiluminescence spectra during the lowtemperature reactions and the main heat release period of HCCI combustion. They found that, depending on the fuel, low-temperature reactions may or may not exist and precede the main heat release. During the main heat release, a continuous, essentially structureless spectrum ranging from 250 to $550 \mathrm{~nm}$ was observed. Furthermore, a strong correlation between the light intensity and the rate of heat release was found. Dec et al. [13] showed that the emission spectrum of combustion in conventional CI engines includes distinct features due to thermal radiation and $\mathrm{OH}^{*}$ chemiluminescence. Kim et al. [14] used spectroscopy to compare HCCI, SCCI and SI combustion of PRF50. They analyzed spectra based on putative point measurements at the center of combustion chamber. In the SI combustion spectra, an $\mathrm{OH}^{*}$ peak was observed during the combustion, while $\mathrm{CH}^{*}$ and $\mathrm{C}_{2}{ }^{*}$ peaks were only present during the early stage of combustion. The main heat release spectra of HCCI combustion were dominated by the $\mathrm{CO}_{2}{ }^{*}$ continuum with superposed formaldehyde bands, but peaks corresponding to $\mathrm{OH}^{*}, \mathrm{CH}^{*}$ and $\mathrm{C}_{2}$ * were not observed. They also reported broadband chemiluminescence during the low-temperature heat release, be it 3-4 orders of magnitude less intense than the luminescence during the main heat release. Augusta et al. [15] investigated the spectral features of HCCI combustion of PRF87 under a wide variety of engine operating conditions. They observed several distinct spectral peaks attributed to $\mathrm{OH}^{*}, \mathrm{CHO}^{*}, \mathrm{CH}^{*}$ and $\mathrm{CH}_{2} \mathrm{O}$, although small, superimposed on top of a $\mathrm{CO}_{2}{ }^{*}$ continuum. Their results were similar for all operating conditions, suggesting that the primary reaction pathways of the fuel remained unchanged in spite of factors that significantly affected HCCI combustion timing and heat release rate.

Many studies have used optical filters to investigate the combustion behavior and detect different species like $\mathrm{OH}^{*}$ and $\mathrm{CH}^{*}[7,11,16,17]$. The obvious advantage of spectral bandpass filters is that they allow spatial distribution mapping; the obvious disadvantage is that one can never exclude spectral interference by other emitters than those for which the filter is intended. $\mathrm{OH}^{*}$ bandpass imaging is typically used as a measure for the rate of heat release in combustion. The equivalence ratio (in premixed laminar flames) is often estimated by means of the intensity ratio between $\mathrm{OH}^{*}$ and $\mathrm{CH}^{*}$ chemiluminescence. The $\mathrm{CH}^{*} / \mathrm{OH}^{*}$ chemiluminescence ratio is found to proportionally increase with equivalence ratio at atmospheric pressures $[18,19]$.

In this paper, we report on optical emission studies of PPC combustion in a light-duty optical CI engine. A method has been developed to distinguish between chemiluminescence by various species $\left(\mathrm{OH}^{*}, \mathrm{C}_{2} *\right.$ and $\mathrm{CH}^{*}$ ) and thermal radiation, based on spectroscopic measurements of the lion's share of the combustion chamber. The effect of charge stratification on the spectral signature of PPC combustion has been investigated for the first time and is compared to homogeneous conditions. Furthermore, a study has been performed on the reliability of bandpass filters when they are used to investigate the auto-ignited combustion in an IC engine. As the final part of this research, broadband chemiluminescence and the $\mathrm{CH} * / \mathrm{OH}^{*}$ intensity ratio are investigated as a proxy for equivalence ratio of low-temperature combustion in an IC engine. 


\section{Experimental setup}

\subsection{Optical engine}

A VOLVO D5 light-duty DI engine is used in this study to obtain the measurement data. The engine is adapted for optical access according to a Bowditch design [20]. A single engine cylinder is equipped with a cylindrical quartz liner with a height of $25 \mathrm{~mm}$ while the other four cylinders are deactivated. A flat optical quartz piston is used to analyze the luminescence from below. This flat piston geometry decreases the amount of premixing with respect to that of a piston bowl. Furthermore, with a flat piston geometry, fuel is more likely to end up in the crevice volume [21]. The advantage of a flat optical piston over a bowl is that the image is not affected by any distortion. To this end, this piston configuration is used to link the research to the results of previous work [16].

Engine specifications are presented in Table 1. The engine is operated by using a dynamometer, and EGR is simulated by diluting the intake air with nitrogen.

The in-cylinder pressure is measured every $0.20 \mathrm{CAD}$ using an AVL GU13P pressure transducer coupled to a KISTLER 5011 charge amplifier. The heat release analysis is based on the time history of the cylinder pressure and the corresponding volume, a single-zone description

Table 1 Engine specifications

\begin{tabular}{ll}
\hline Displacement & $480 \mathrm{cc} /$ cylinder \\
\hline Bore & $81 \mathrm{~mm}$ \\
Stroke & $93.2 \mathrm{~mm}$ \\
Connecting rod length & $147 \mathrm{~mm}$ \\
Compression ratio & $12.6: 1$ \\
Fuel & PRF70 \\
Number of injector holes & 7 \\
Injector umbrella angle & $140^{\circ}$ \\
Injector diameter hole & $140 \mu \mathrm{m}$ \\
Injection pressure & $600 \mathrm{bar}$ \\
\hline
\end{tabular}

of the cylinder contents with thermodynamic properties, Woschni's heat-loss model and including a crevice model [22, 23]. A fifth-order Hann window function is applied to reduce the noise on the pressure and heat release trace.

\subsection{Operating conditions}

The engine is operated at $1200 \mathrm{rpm}$ in skip-fire mode (once every 10 engine cycles) to lower the loads on the quartz liner. For each measurements point, 30 firing cycles are recorded. When investigating different combustion modes, CA50 is held constant for five different single injection timings (different ignition delays) using direct injection at an injection pressure of 600 bar. The set of parameters for each injection timing are presented in Table 2; for all cases, the amount of injected fuel is approximately $17 \mathrm{mg} / \mathrm{cycle}$. The intake pressure and the cylinder wall temperature are kept constant at 1.2 bar and $363 \mathrm{~K}$, respectively.

The pressure and heat release rate curves for different injection timings (cases A-E of Table 2) are presented in Fig. 1. In case A, homogeneous combustion is achieved by injecting early, well before TDC. Cases C, D and E all represent partially premixed combustion with different injection timings and therefore different charge stratification levels, whereas case B can be classified as a transition point from HCCI to PPC. Case E, having the latest injection timing, causes the sharpest rate of heat release (ROHR) since higher local equivalence ratios (closer to stoichiometric) are formed for this case.

To allow for investigation of equivalence ratios, the injection duration is slightly varied for injection strategies $\mathrm{A}$ and $\mathrm{C}$. The corresponding sets of parameters are presented in Table 3. In order to maintain a constant airflow and a similar CA50, the intake pressure and temperature are slightly tuned. The global equivalence ratios for all experimental points are reported in Tables 2 and 3. However, for PPC operating points the local equivalence ratios are likely to be much different from the global ones. For that reason, we have used the injected fuel mass for labeling the results of PPC points in the next sections.

Table 2 Single injection strategies

\begin{tabular}{llllllll}
\hline Case & $\begin{array}{l}\text { Injection timing } \\
(\mathrm{CAD})\end{array}$ & $\begin{array}{l}\text { Injection duration } \\
(\mathrm{CAD})\end{array}$ & $\mathrm{CA50}(\mathrm{CAD})$ & $\begin{array}{l}\text { Intake tempera- } \\
\text { ture (K) }\end{array}$ & $\begin{array}{l}\text { Oxygen percent- } \\
\text { age (vol-\%) }\end{array}$ & $\begin{array}{l}\text { Airflow (g/s) } \\
\begin{array}{l}\text { Global } \\
\text { Equivalence } \\
\text { ratio (-) }\end{array}\end{array}$ \\
\hline A & -200 & 5.6 & 8 & 323 & 19.0 & 6.8 & 0.40 \\
B & -50 & 5.4 & 9 & 348 & 19.0 & 6.8 & 0.39 \\
C & -25 & 5.4 & 9 & 348 & 18.8 & 6.7 & 0.40 \\
D & -20 & 5.4 & 10 & 343 & 19.0 & 6.5 & 0.39 \\
E & -15 & 5.5 & 10 & 413 & 18.8 & 0.41 \\
\hline
\end{tabular}

Total injected fuel is approximately $17 \mathrm{mg} /$ cycle in all cases 


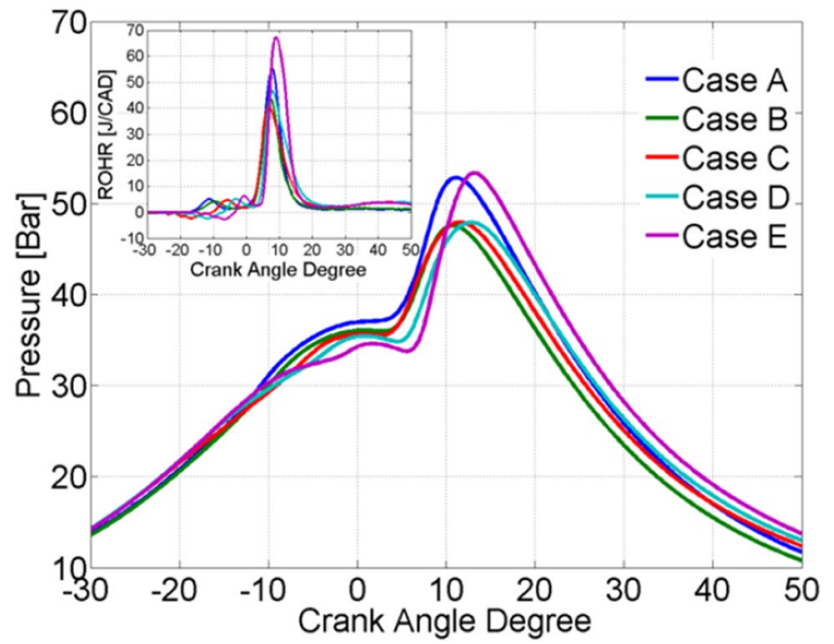

Fig. 1 Pressure and heat release rate for different charge stratification levels (Table 2)

Table 3 Single injection strategies for varying equivalence ratio

\begin{tabular}{lllll}
\hline Case & $\begin{array}{l}\text { Intake pres- } \\
\text { sure (bar) }\end{array}$ & $\begin{array}{l}\text { Intake tem- } \\
\text { perature }(\mathrm{K})\end{array}$ & $\begin{array}{l}\text { Injected fuel } \\
\text { mass (mg/cycle) }\end{array}$ & $\begin{array}{l}\text { Global } \\
\text { Equivalence } \\
\text { ratio (-) }\end{array}$ \\
\hline $\mathrm{A}$ & 1.18 & 303 & 19.70 & 0.44 \\
& 1.20 & 323 & 18.14 & 0.40 \\
& 1.21 & 348 & 16.58 & 0.36 \\
& 1.22 & 348 & 15.02 & 0.33 \\
$\mathrm{C}$ & 1.18 & 318 & 18.92 & 0.44 \\
& 1.20 & 348 & 16.97 & 0.40 \\
& 1.21 & 373 & 15.02 & 0.35 \\
& 1.22 & 398 & 13.07 & 0.31 \\
\hline
\end{tabular}

Operating conditions correspond to Table 2

\subsection{Spectroscopy method}

Crank-angle-resolved spectroscopic measurements are performed by coupling a high-speed intensified camera (Lambert HiCAM 5000) to a grating spectrograph (Acton SP$300 i)$. Combustion luminescence is recorded through the quartz piston, via the $45^{\circ}$ mirror (Fig. 2); under the operating conditions selected here, window fouling was found to be negligible. The field of view (FOV) of the spectrograph comprises a tangential section through the cylinder to always focus on multiple combustion clouds (red line in Fig. 1.). Specifications of the detection setup are presented in Table 4.

A mercury vapor lamp is used for calibration of the spectrograph. The spectrograph imaging system deforms the detected image. In Fig. 3a, this pincushion distortion is illustrated for one of the mercury vapor emission lines. All images are corrected for pincushion distortion as depicted

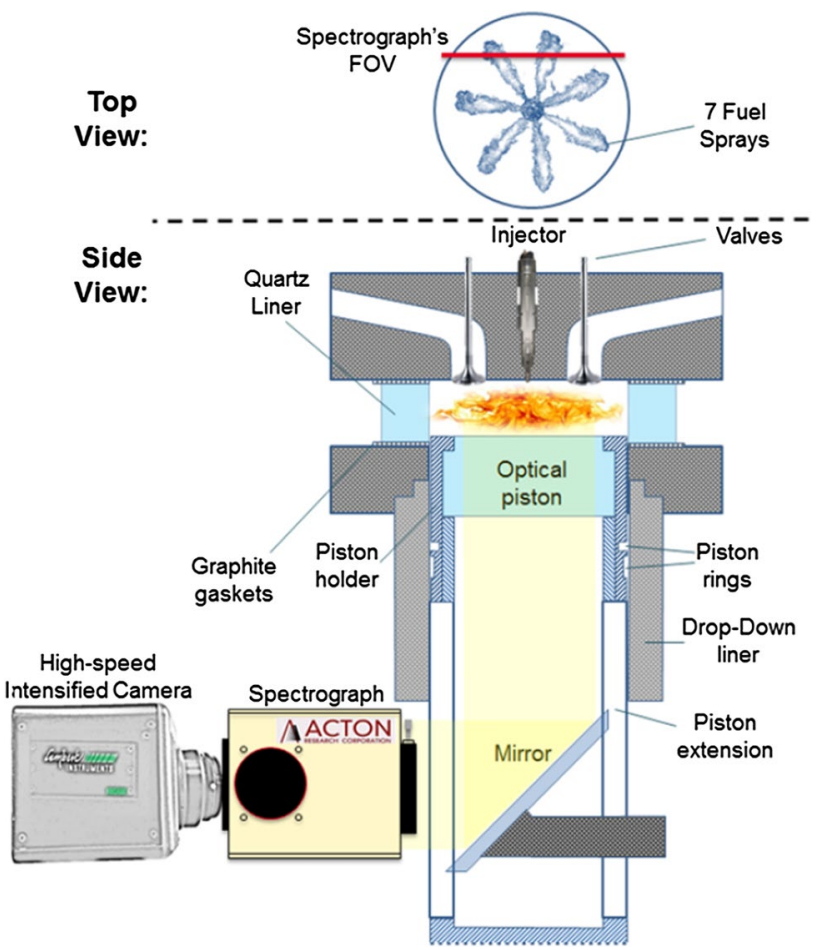

Fig. 2 Hybrid schematic of the optical engine and the spectroscopy setup

in Fig. 3b. Later, the calibration is performed by relating the camera pixels to corresponding wavelength by means of the mercury spectrum as shown in Fig. 3c. This linear correlation is based on the first six peak positions.

The quantum efficiency of the intensified camera changes over the wavelength range as illustrated in Fig. 3d (based on the manufacturer data sheet). The grating efficiency of the spectrograph is also affecting the acquired spectra. The grating used in our experiments has a groove frequency of $150 \mathrm{l} / \mathrm{mm}$ and is blazed at $500 \mathrm{~nm}$. In Fig. 3d, the grating efficiency curve is included as well. These data are combined to scale the spectra to constant detection efficiency. Since the transmission efficiency and collection angle of the other optics in the setup is constant over the whole wavelength range, no further correction was required.

\section{Spectroscopy analysis}

The spectroscopic measurements provide spectral and temporal information regarding the combustion $[8,9,11]$. The objective of these measurements is to correlate the chemiluminescence intensities of five different components, including thermal radiation, broadband chemiluminescence, and relatively narrowband $\mathrm{OH}^{*}, \mathrm{CH}^{*}$ and $\mathrm{C}_{2}{ }^{*}$ emission, in the PPC combustion regime. To achieve the goal, the 
Table 4 Specifications of the camera and spectrograph

\begin{tabular}{ll}
\hline Camera & Lambert HiCAM 5000 (built-in intensifier) \\
\hline Imaging sensor & 8 bits CMOS \\
Resolution & $512 \times 512$ pixels \\
Frame rate & $3600 \mathrm{fps}$ \\
Exposure time & $250 \mu \mathrm{s}$ \\
Objective lens & UV Bernhard Halle Nachfl. $100 \mathrm{~mm} \mathrm{f} / 2$ \\
Spectrograph & Princeton Acton SP-300i \\
Groove frequency & $1501 / \mathrm{mm}$ \\
Blaze & $500 \mathrm{~nm}$ \\
Wavelength range & $270-540 \mathrm{~nm}$ \\
Linear dispersion & $10.5 \mathrm{~nm} / \mathrm{mm}$ \\
\hline
\end{tabular}
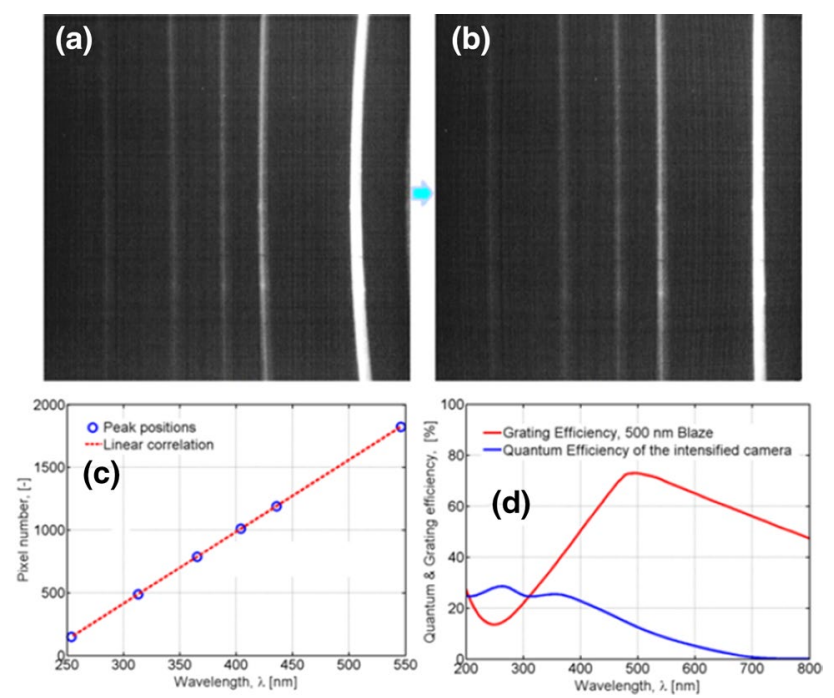

Fig. 3 a Distorted image of the mercury vapor lamp spectrum. b Correction of the distorted image. $\mathbf{c}$ Calibration of spectrograph using mercury vapor lamp. d Spectrograph grating efficiency and camera quantum efficiency curves

spectral signature over a wavelength range of $270-540 \mathrm{~nm}$ is recorded simultaneously. Spectra are integrated over the entire FOV and scaled to constant detection efficiency, as explained above. The contribution of thermal (black body) radiation is estimated based on Planck's law. The remaining broadband luminescence is attributed to chemiluminescence of relatively large molecules, like $\mathrm{HCO}^{*}, \mathrm{H}_{2} \mathrm{CO}^{*}$ and $\mathrm{CO}_{2}{ }^{*}$. The contributions of $\mathrm{OH}^{*}, \mathrm{C}_{2} *$ and $\mathrm{CH}^{*}$ are determined based on their relatively narrowband emission in characteristic spectral ranges, as detailed below. Our desire to record a large spectral range simultaneously comes with a relatively low spectral resolution. Therefore, no attempt has been made to analyze spectral envelopes of the narrowband contributions.

Initially, the thermal radiation intensity was separated from the total spectrum. This has been done by evaluating the wavelength range of 500-540 $\mathrm{nm}$ and fitting Planck's law to the data. This wavelength range $(500-540 \mathrm{~nm})$ is less than desirable but the maximum that could be achieved given the spectrometer and the fact that the entire $\mathrm{OH}^{*}$ band (on the other end of the spectral range) was to be acquired simultaneously. Here, Planck's law is described as

$I(\lambda)=A \frac{2 h c^{2}}{\lambda^{5}} \frac{1}{e^{h c /\left(\lambda k_{\mathrm{b}} T\right)}-1}$,

where $c$ represents the speed of light $[\mathrm{m} / \mathrm{s}], h$ and $k_{\mathrm{b}}$ represent the Planck constant $\left[\mathrm{m}^{2} \mathrm{~kg} / \mathrm{s}\right]$ and the Boltzmann constant $\left[\mathrm{m}^{2} \mathrm{~kg} /\left(\mathrm{s}^{2} \mathrm{~K}\right)\right]$, respectively, $\lambda$ is the wavelength [m], $T$ represents the temperature $[\mathrm{K}]$ and $A$ is a scaling factor. The unknown values for $A$ and $T$ are scaled such that Planck's law fits the data best; see Fig. 4 for an example. It should be noted that the good fit found in this particular figure is not representative for all cases. In the example of Fig. 5, broadband chemiluminescence dominates the spectrum, and the restricted wavelength range available for Eq. (1) does not allow to distinguish a separate contribution due to thermal radiation. We used the threshold criterion of 0.8 for the coefficient of determination $\left(R^{2}\right)$ for the correlation between Planck's law and the experimental data. This threshold $R^{2}$ value is based on visual inspection of a large number of spectra. When the criterion is met $\left(R^{2}>0.8\right)$, we consider thermal radiation to contribute perceptibly to the total spectrum. We realize that the choice of the value of 0.8 is arbitrary, but ascertained that the results do not vary significantly for cutoff values in the range 0.7-0.9. The net contribution of the thermal radiation is then defined by integrating Planck's law over the full observed wavelength range. When the threshold criterion is not met, any contribution of the thermal radiation is included in the broadband

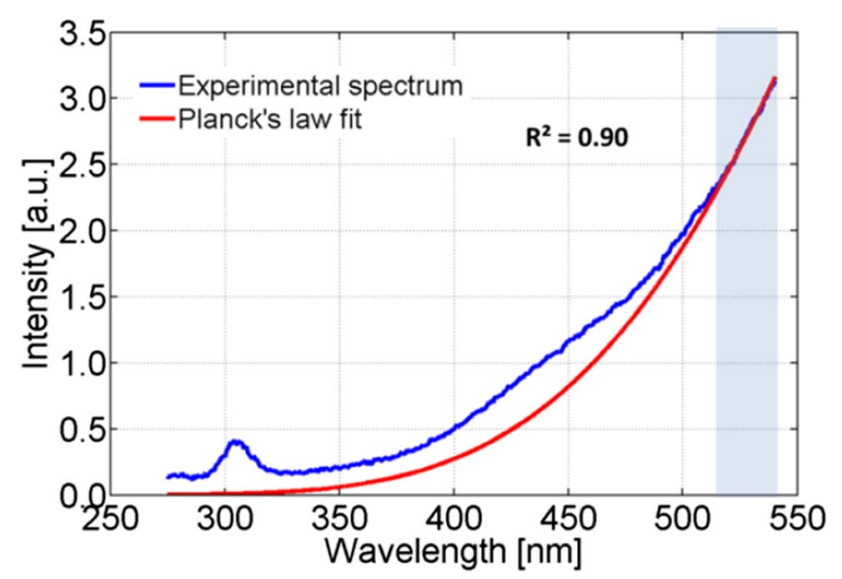

Fig. 4 Planck's law fitted to the obtained spectrum (case C, injected fuel mass: $16.97 \mathrm{mg} /$ cycle, 23 CAD ATDC) 


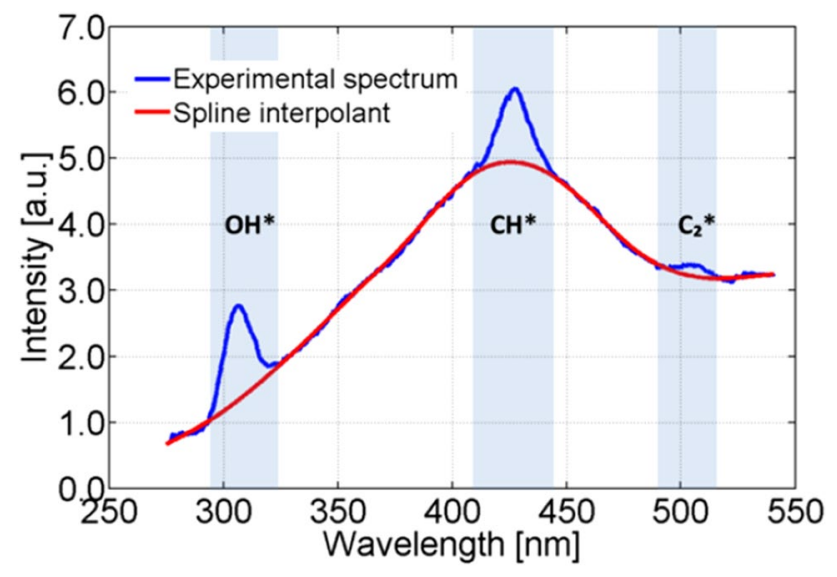

Fig. 5 A smooth spline fitted to the obtained spectrum (case C, injected fuel mass: $16.97 \mathrm{mg} /$ cycle, 5 CAD ATDC)

chemiluminescence, discussed later in this section. In fitting Planck's law, we limit temperature between 1000 and $2500 \mathrm{~K}$. However, for $R^{2}>0.8$ the best-fit temperature is always between 2000 and $2400 \mathrm{~K}$, and it decreases toward the end of combustion.

After subtraction of the thermal component (if present), in the remaining spectra a broadband signal is observed, stretching from approx. 300 to $500 \mathrm{~nm}$. The literature relates this broadband spectrum to chemiluminescence of relatively large molecules like $\mathrm{HCO}^{*}, \mathrm{CH}_{2} \mathrm{O}^{*}$ and $\mathrm{CO}_{2} *$ [24]. In order to separate the narrower $\mathrm{OH}^{*}, \mathrm{CH}^{*}$ and $\mathrm{C}_{2} *$ chemiluminescence from this broadband chemiluminescence, a smooth spline is fitted, based on the data in the wavelength ranges outside the well-defined $\mathrm{OH}^{*}, \mathrm{CH}^{*}$ and $\mathrm{C}_{2}{ }^{*}$ spectral ranges of 285-320, 415-445 and 495-516 nm, respectively (indicated by shading in Fig. 5). Then, a spline interpolation is made in the shaded wavelength ranges. Again, this broadband chemiluminescence signal is subtracted from the total spectrum and integrated over the observed wavelength range to obtain a measure for this signal.

In Fig. 5, it is observed that the spectrum still might include some thermal radiation. However, in this particular experiment Planck's law does not correlate well to the data: $R^{2}<0.8$. This implies that in some measured spectra, especially within the early stage of combustion, the thermal radiation coincides with the broadband chemiluminescence signal and the measure for broadband chemiluminescence signal includes some thermal radiation. Evaluating a larger wavelength range (extended to the red) could overcome this problem, but this was not feasible with our available equipment.

An example of a remaining spectrum, after subtraction of both thermal and broadband chemiluminescence contributions, is displayed in Fig. 6. Due to finite spectrograph resolution and pressure broadening, species peaks are relatively broad. In order to define a measure for $\mathrm{OH}^{*}$,

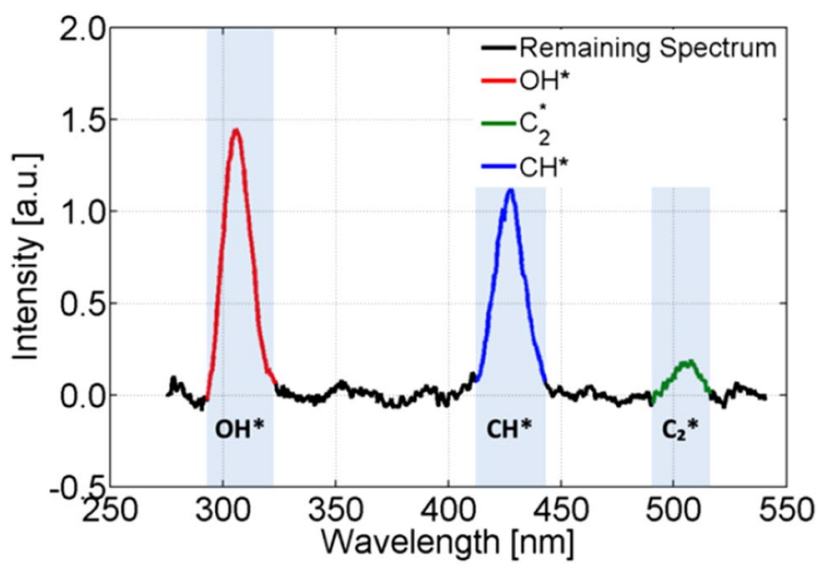

Fig. 6 Typical remaining spectrum after subtraction of thermal radiation and broadband chemiluminescence (case $\mathrm{C}$, injected fuel mass: $16.97 \mathrm{mg} /$ cycle, $5 \mathrm{CAD}$ ATDC). $\mathrm{OH}^{*}, \mathrm{CH}^{*}$ and $\mathrm{C}_{2}{ }^{*}$ wavelength ranges are indicated

$\mathrm{CH}^{*}$ and $\mathrm{C}_{2} *$ chemiluminescence, the intensity is integrated from 285 to 320,415 to 445 and 495 to $516 \mathrm{~nm}$, respectively.

\section{Results and discussion}

Spectroscopy measurements have been performed for different combustion modes. All results presented in this section are mean values over 30 engine cycles in a single experiment. A high level of cycle-to-cycle repeatability is observed for the experimental points. First, the effect of combustion stratification is investigated, followed by the assessment of the reliability of the bandpass filters and the relation to heat release rate. Finally, the effect of equivalence ratio has been investigated.

\subsection{Effect of combustion stratification}

Figure 7 displays the spectra for HCCI and PPC combustion at CA50. Clear differences can be noted; the PPC spectrum shows distinct features like $\mathrm{OH}^{*}, \mathrm{CH}^{*}$ and $\mathrm{C}_{2}$ * chemiluminescence, whereas the HCCI spectrum only shows broadband chemiluminescence. As expected, HCCI combustion does not show thermal radiation at all. Also, there is almost no thermal radiation for the PPC points at CA50. However, thermal radiation is seen for PPC later in the combustion.

In order to highlight different aspects of the results, different normalization procedures are used. For Fig. 8, the time-integrated (cyclic) intensities attributed to individual sources are normalized by the total luminosity throughout the combustion cycle: 


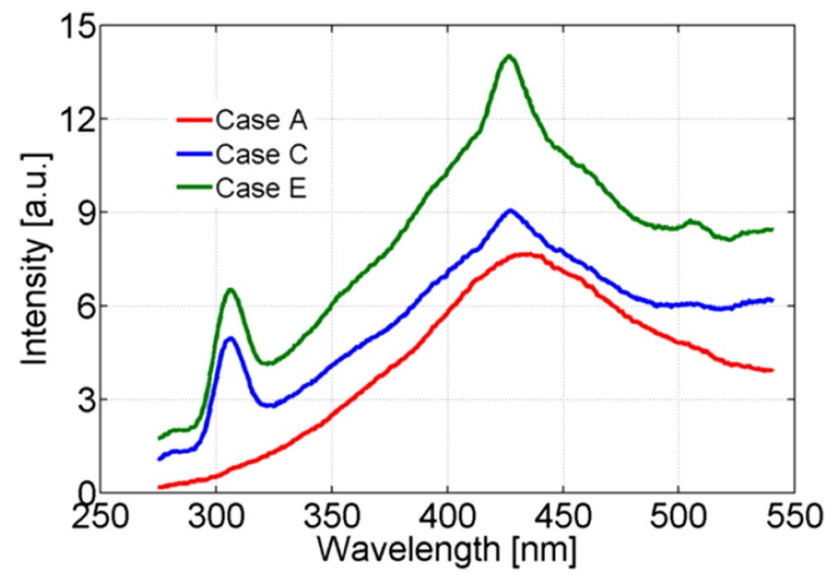

Fig. 7 Spectra of HCCI (case A) and PPC (cases C and E) combustion at CA50. See Table 2 for operating conditions

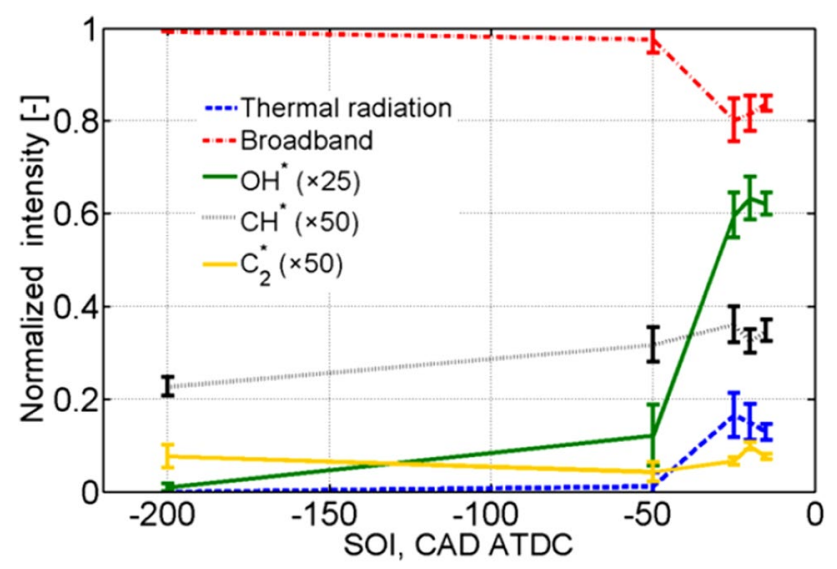

Fig. 8 Cyclic normalized intensity versus start of injection. Standard deviations over 30 measurement cycles are indicated

$\bar{I}_{\mathrm{cl}}(\mathrm{sp})=\frac{\int^{\mathrm{sp}} \mathrm{d} \lambda \int_{-180}^{+180} I_{\mathrm{sp}}(\lambda, \mathrm{CA}) \mathrm{dCA}}{\int_{270}^{540} \mathrm{~d} \lambda \int_{-180}^{+180} I(\lambda, \mathrm{CA}) \mathrm{dCA}}$,

where sp indicates integration over a wavelength range characteristic for a particular species, $\lambda$ is wavelength [nm], $\mathrm{CA}$ is crank angle degree (CAD), $I(\lambda, \mathrm{CA})$ is the total recorded intensity as a function of wavelength and time, $I_{\mathrm{sp}}(\lambda, \mathrm{CA})$ is the contribution of either thermal radiation (Fig. 4), the spline interpolant for broadband chemiluminescence (Fig. 5), or the individual species intensity for $\mathrm{OH}^{*}, \mathrm{CH}^{*}$ and $\mathrm{C}_{2} *$ chemiluminescence (Fig. 6).

In Fig. 8, these normalized integrated intensities of different species $\left(\bar{I}_{\mathrm{cl}}(\mathrm{sp})\right)$ are presented as a function of SOI timing, to illustrate the effect of charge stratification on combustion behavior. For $\mathrm{OH}^{*}, \mathrm{CH}^{*}$ and $\mathrm{C}_{2}{ }^{*}$ chemiluminescence, intensities are multiplied by factors of 25,50 and 50 , respectively, for the sake of clarity. For homogeneous combustion points (early SOI, so long ignition delay), the predominant source of combustion luminosity is broadband chemiluminescence. Hardly any thermal radiation is detected and narrowband chemiluminescence is all but absent as well. By moving from HCCI to PPC regime, the thermal contribution increases. Most likely, the latter is due to locally increased equivalence ratios (closer to stoichiometric) that give rise to enhanced formation of soot [3]. Furthermore, $\mathrm{OH}^{*}, \mathrm{CH}^{*}$ and $\mathrm{C}_{2} *$ chemiluminescence intensities all increase upon increasing charge stratification (as a consequence of moving from HCCI to PPC). This increase can be related to the influence of combustion temperature; locally higher equivalence ratios result in higher combustion temperature, and this elevated temperature can be the cause of enhanced chemiluminescence. However, the exact chemical processes behind chemiluminescence are not sufficiently well known to provide definitive answers to the phenomena, particularly at elevated pressure [12, 25].

Time-resolved results for various species are presented in Fig. 9. In this figure, all curves are individually normalized such that their maximum values equal 1 . This allows convenient comparison of peak timings of different luminosity sources. In the top graph of Fig. 9, this is done for HCCI combustion; in the bottom graph, the behavior for PPC is illustrated. It is observed that HCCI combustion proceeds very fast, all luminosity sources observed culminate simultaneously. Furthermore, the luminosity behavior corresponds to that of the rate of heat release. Similar to Fig. 8, $\mathrm{OH}^{*}$ chemiluminescence and thermal radiation are not detected in this combustion mode. This spectral signature is similar to what Kim et al. [14] reported for HCCI combustion of PRF50. However, we did not see any spectral emission during the ignition delay and the low-temperature heat release, while Kim et al. reported a broadband emission with 3-4 orders of magnitude less intensity than the one during the main heat release. The absence of the spectral emission during the ignition delay of HCCI was also indicated by Augusta et al. [15], which is in agreement with our results.

For PPC combustion, however, it is observed that $\mathrm{C}_{2}{ }^{*}$ and $\mathrm{CH}^{*}$ chemiluminescence culminate first during the combustion. Subsequently, broadband and $\mathrm{OH}^{*}$ chemiluminescence reach their peak simultaneously with the rate of heat release, whereas thermal radiation is typically dominant during the late phase of combustion, similar to conventional diffusion combustion. The early peak in $\mathrm{C}_{2}{ }^{*}$ and $\mathrm{CH}^{*}$ chemiluminescence is likely due to the breakup of big molecules during the early stage of combustion, seen in highly turbulent premixed flames as well [26]. Around $+45 \mathrm{CAD}$, a second, broader maximum is observed for all species, which is presumably caused by the burning of fuel escaping from crevice volumes [16]. The high piston clearance in our optical engine $(1 \mathrm{~mm})$ is the main cause of a significant amount of trapped fuel, which would not be expected for a metal engine.

In Fig. 14 in "Appendix", the crank-angle-resolved results of different species for different injection timings 


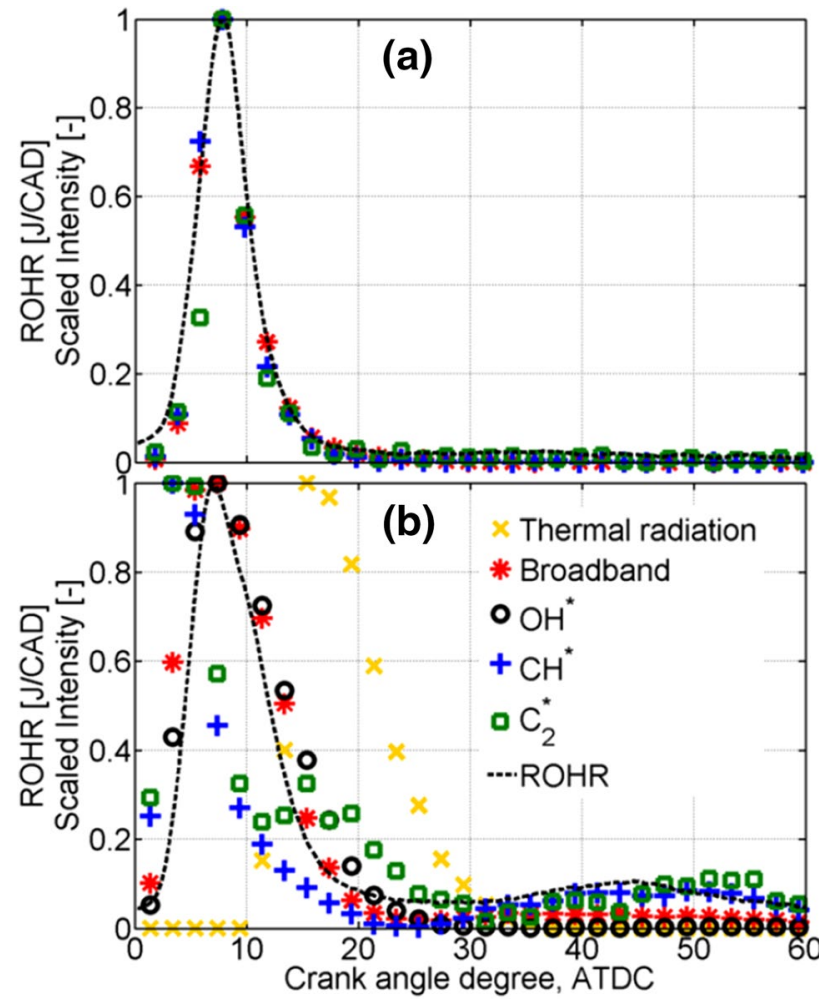

Fig. 9 Crank-angle-resolved behavior of different species for a HCCI combustion (case A) and $\mathbf{b}$ PPC combustion (case C), averaged over 30 cycles

are compared. By looking in more detail to Fig. $9 \mathrm{~b}$ around $+15 \mathrm{CAD}$, it can be seen that the $\mathrm{C}_{2} *$ intensity increases a little bit where thermal radiation starts to be detectable. This behavior can also be seen for PPC points in Figs. 10 and 14, especially for higher equivalence ratios: where thermal radiation of soot particles is maximum a second peak is seen for $\mathrm{C}_{2}$ *. This is in agreement with results of Merola et al. [27] for the late stage of conventional diesel combustion. It can be concluded that there are two different chemical mechanisms for formation of $\mathrm{C}_{2}$ * in the PPC regime: first during the early stage of combustion by the breakup of larger molecules and the second during the late stage of combustion when soot particles are forming.

\subsection{Adequacy of bandpass filters}

Since the observation is made that broadband chemiluminescence is dominant for both HCCI and PPC regimes, the question arises what is exactly investigated in studies that only apply optical bandpass filters to detect particular species in these combustion regimes. This is analyzed on the basis of our spectra for different levels of combustion stratification. Virtual $\mathrm{OH}^{*}, \mathrm{CH}^{*}$ and $\mathrm{C}_{2} *$ bandpass filters are applied to the recorded spectra to obtain integrated intensities in the wavelength regions of $285-320 \mathrm{~nm}\left(\mathrm{OH}^{*}\right), 415-445 \mathrm{~nm}\left(\mathrm{CH}^{*}\right)$ and $495-516 \mathrm{~nm}\left(\mathrm{C}_{2}{ }^{*}\right)$; see shading in Fig. 5. Also, the actual contribution of each species in its bandpass region is calculated by integrating the spectra after subtraction of all broadband contributions; see Figs. 5 and 6 for an example. The ratio of each species contribution to the total intensity in the corresponding filter region results in the percentage of that species at a given CA. The results are presented in Fig. 11.

It is observed from Fig. 11 that the adequacy of an optical filter to detect $\mathrm{C}_{2}{ }^{*}$ and $\mathrm{CH}^{*}$ chemiluminescence is almost void for all combustion modes, due to the broadband chemiluminescence. For homogeneous condition cases (large ID), the percentage of $\mathrm{OH}^{*}$ chemiluminescence is even negligible. The increase in $\mathrm{CH}^{*}$ and $\mathrm{C}_{2}{ }^{*}$ chemiluminescence percentage around 30-60 CAD ATDC is due to trapped fuel that escapes the crevices and burns [16]. Concluding, even though the use of optical filters is indispensable for obtaining spatial information during combustion, the transmitted signal may largely be due to other chemical compounds than intended.

\subsection{Chemiluminescence and rate of heat release}

In previous publications $[9,16,17], \mathrm{OH}^{*}$ chemiluminescence intensity measured through bandpass filters has been used as a proxy for the local rate of heat release. Since Fig. 11 illustrates that the percentage of actual $\mathrm{OH}^{*}$ signal observed through $\mathrm{OH}^{*}$ bandpass filters is often negligible, one may wonder whether the luminosity recorded through $\mathrm{OH}^{*}$ bandpass filters is still a measure for the heat release or not. To this end, the HCCI experiments with different equivalence ratios are analyzed (see Table 3, case A). Figure 12a shows the scaled accumulated intensity obtained through a virtual $\mathrm{OH}^{*}$ bandpass filter from CA10 to CA90 versus the scaled heat released in these experiments. The heat release period from CA10 to CA90 is chosen to focus only on the main heat release. Hence, the low-temperature heat release, which is not accompanied by any emission, and the afterburning of trapped fuel, which is far from homogeneous, are not considered in Fig. 12. A linear relation is observed with a high coefficient of determination. The residual scatter of data points is probably due not so much to low signal-to-noise ratios but rather to the relatively large time step between recorded images (compared to the heat released data) and the limited FOV of the spectrograph, which is merely a line, whereas the heat release is volumetric. Still, these results indicate that the intensity observed through $\mathrm{OH}^{*}$ optical bandpass filters indeed can be used as a measure for the rate of heat release even though the signal is hardly a measure for $\mathrm{OH}^{*}$ at all. This analysis has been repeated for the total range of broadband chemiluminescence in Fig. 12b. A similar linear relation results, which shows that the broadband chemiluminescence can be taken as a measure for the heat release rate, 

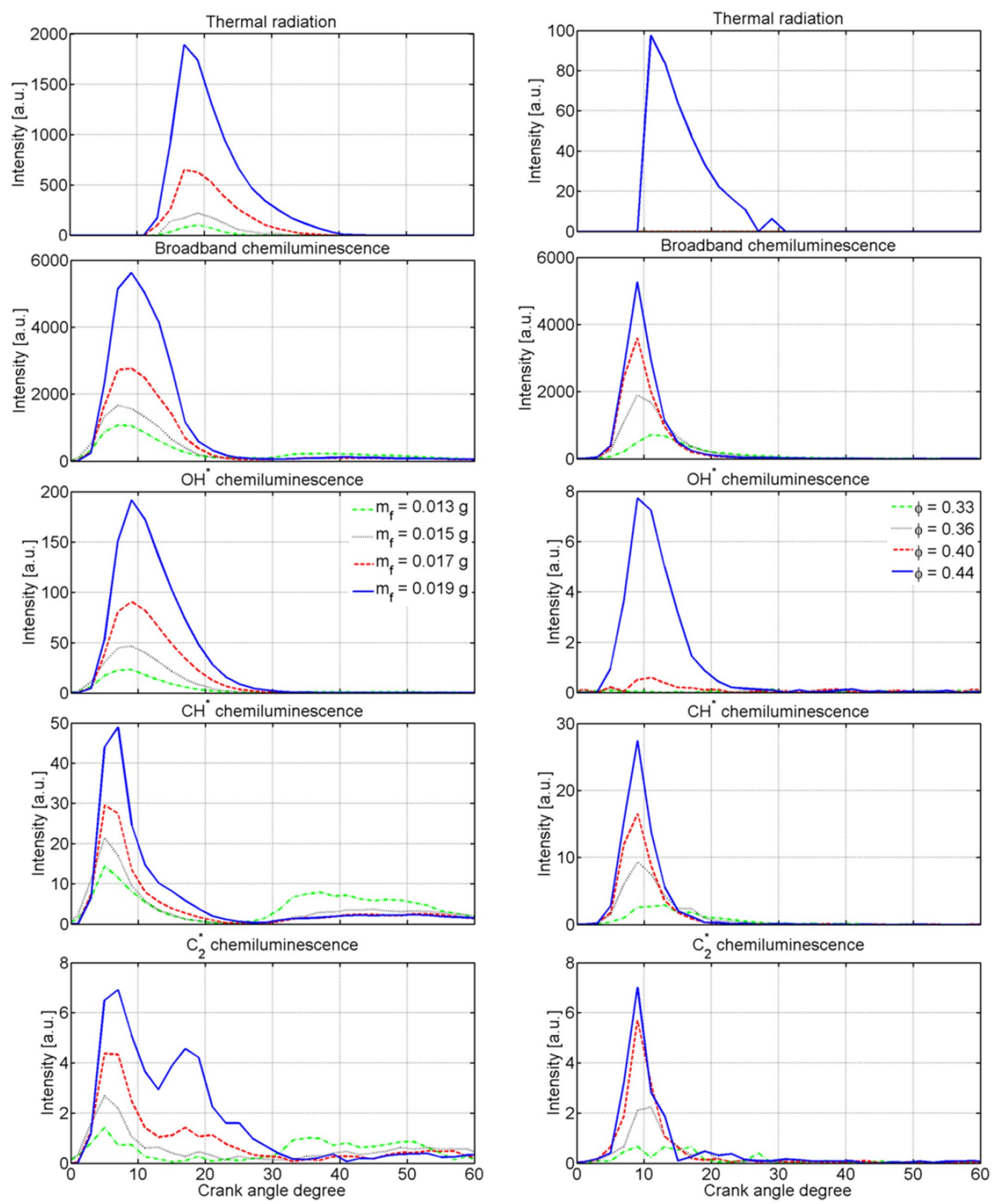

Fig. 10 Time-resolved species chemiluminescence intensities for varying injected fuel mass. Left SOI -25 CAD ATDC (case C). Right SOI -200 CAD ATDC (case A) 

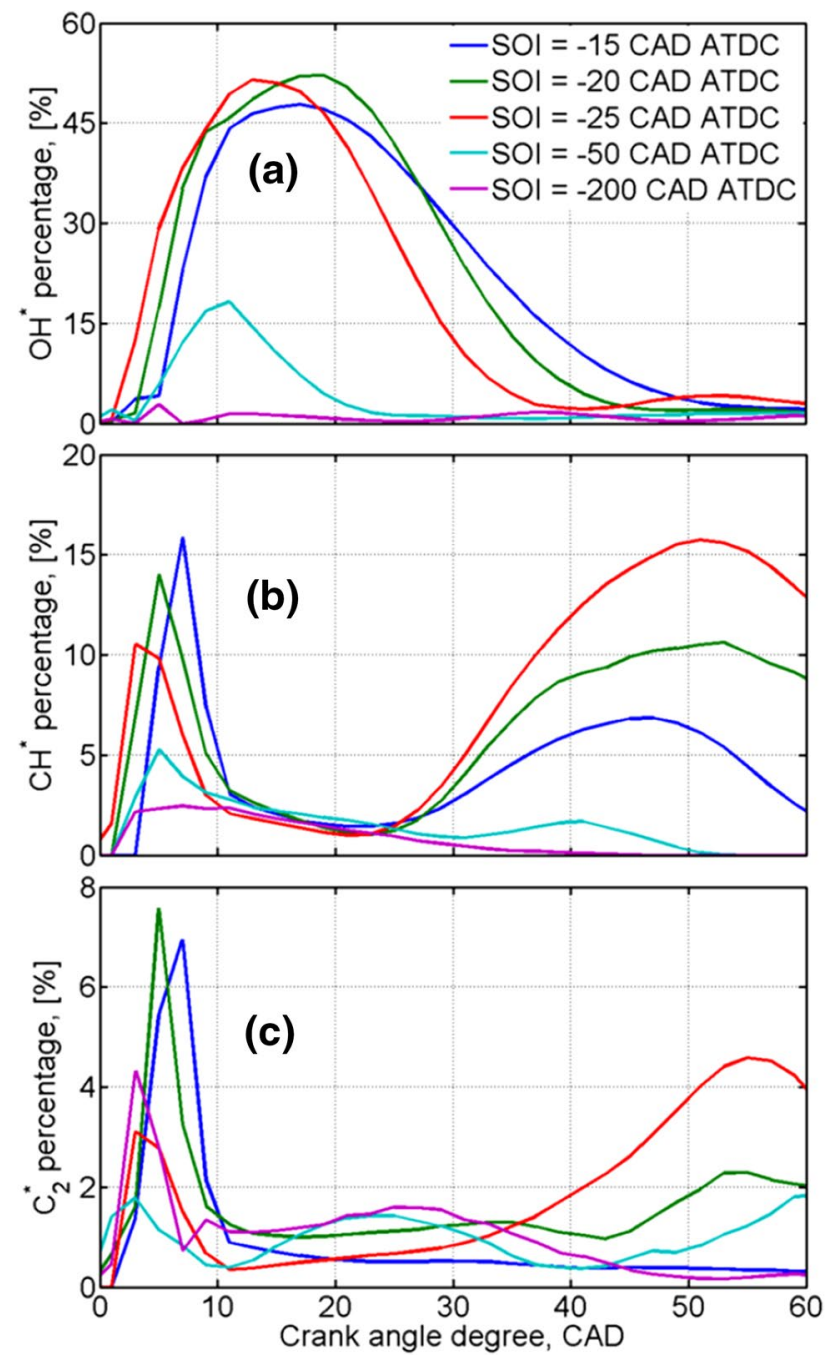

Fig. 11 Adequacy of optical filters to detect $\mathrm{OH}^{*}(\mathbf{a}), \mathrm{CH}^{*}(\mathbf{b})$ and $\mathrm{C}_{2} *$ (c) chemiluminescence. The ordinate represents the percentage of the signal observed through a bandpass filter that is actually due to the intended species

in this combustion mode. The same relation can already be seen in Fig. 9a, where the rate of heat release corresponds to the broadband chemiluminescence signal. This analysis is only done for HCCI combustion, because the limited FOV of the spectrograph in the stratified combustion mode (PPC) is not sufficiently representative to be used for comparison with the volumetric heat release.

\subsection{A proxy for equivalence ratio}

The effect of equivalence ratio on the spectral signature of combustion has been investigated for all operating conditions in Table 3. Figure 10 illustrates the wavelength-integrated signal intensities of different components. It is observed that increasing the injected fuel mass leads to an overall increase in luminescence, but otherwise nothing much happens.

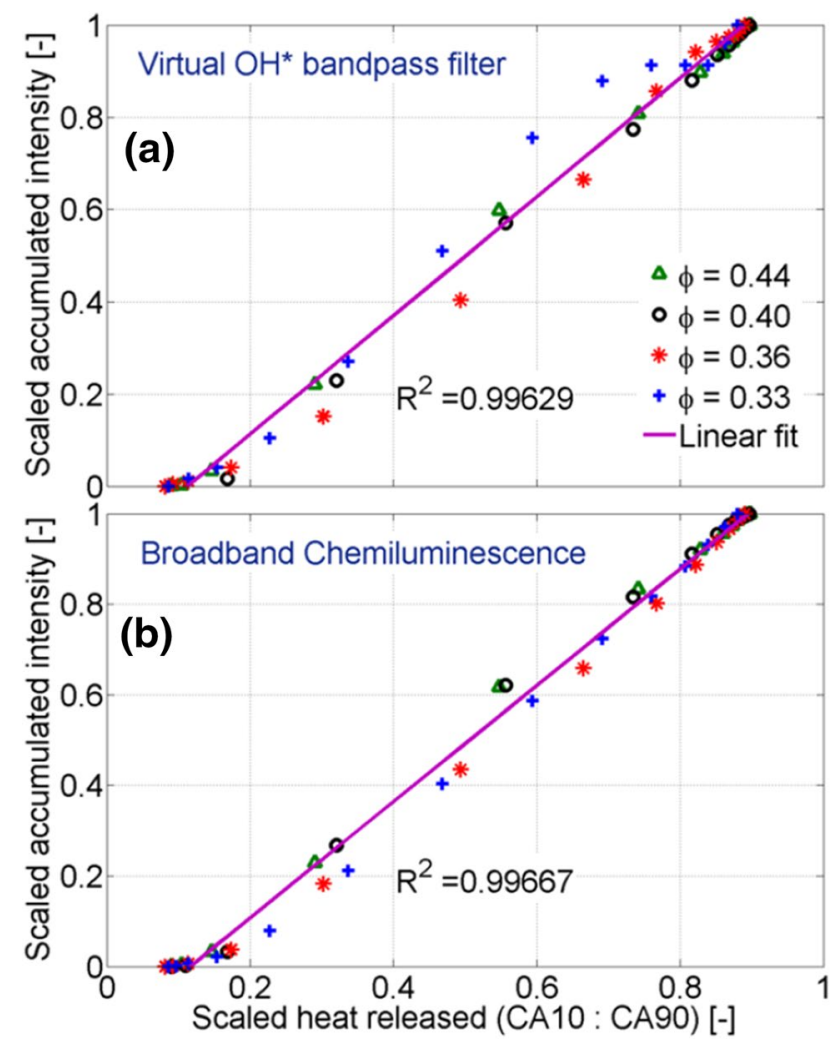

Fig. 12 Relation between virtual $\mathrm{OH}^{*}$ bandpass filter intensity (a), broadband chemiluminescence (b) and the scaled heat released for several equivalence ratios in HCCI mode

Regarding HCCI points, it is shown that the thermal radiation and $\mathrm{OH}^{*}$ chemiluminescence are absent for low equivalence ratios and significantly increase for the highest measured equivalence ratio $(\varphi=0.43)$. However, the signal intensity of $\mathrm{OH}^{*}$ chemiluminescence is still three orders of magnitude less than the broadband chemiluminescence in this point, supporting the low adequacy of using $\mathrm{OH}^{*}$ optical filters for detecting the $\mathrm{OH}^{*}$ signal discussed in Sect. 3.2.

Finally, the average $\mathrm{OH}^{*} / \mathrm{CH}^{*}$ chemiluminescence ratio is investigated for PPC conditions (case C). This analysis has been done for various amounts of injected fuel, and the results are depicted as a function of CAD in Fig. 13a. This figure shows that the average $\mathrm{OH}^{*} / \mathrm{CH}^{*}$ chemiluminescence ratio increases with increasing equivalence ratio. An opposite relation is observed in premixed laminar flames [28]. This difference may be caused by the elevated in-cylinder pressure, turbulence, or flame stretch phenomena, as suggested by Nori et al. [28]. Similar observations are made by Nori et al. [28], who observed a monotonic decrease in the $\mathrm{OH}^{*} / \mathrm{CH}^{*}$ intensity ratio upon increasing the equivalence ratio at atmospheric pressure for methane combustion. For elevated pressures, however, they observed a monotonic increase in the $\mathrm{OH}^{*} / \mathrm{CH}^{*}$ intensity ratio upon increasing the equivalence ratio. Furthermore, they concluded that the $\mathrm{OH}^{*} / \mathrm{CH}^{*}$ ratio can be used for 

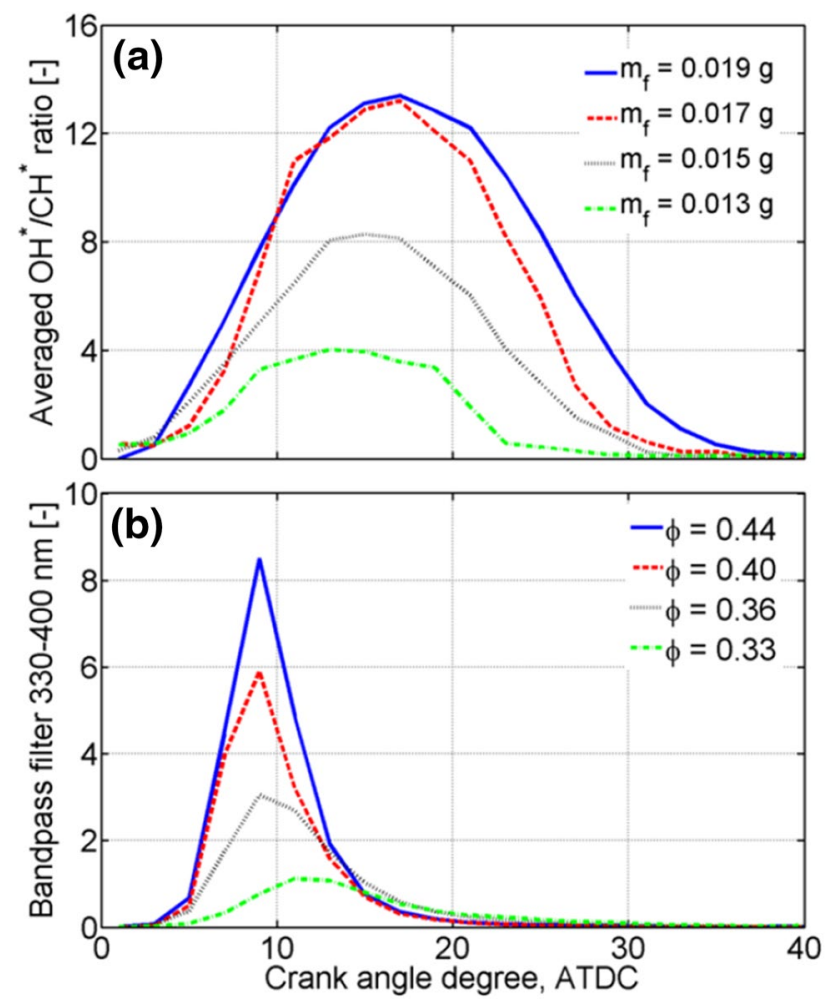

Fig. 13 Average $\mathrm{OH}^{*} / \mathrm{CH}^{*}$ ratio for different amounts of injected fuel of case C (a) and 330-400 bandpass filter for different equivalence ratios of case $\mathrm{A}(\mathbf{b})$

equivalence ratio sensing, but only at certain conditions. Since in-cylinder pressure varies dramatically over a stroke in an IC engine, it is impossible to consider the $\mathrm{OH}^{*} / \mathrm{CH}^{*}$ ratio as representative of equivalence ratio. But there may be an alternative. Figure 10 shows a strong correlation between equivalence ratio and broadband chemiluminescence intensity for both HCCI and PPC cases. We suggest using bandpass filters in the range of 330-400 $\mathrm{nm}$ to collect pure broadband chemiluminescence as a proxy of local equivalence ratio during combustion as shown in Fig. 13b. Note that this method demands precise calibration and further investigations.

\section{Conclusions}

The objective of this study was to evaluate the spectral signature of partially premixed combustion at different stratification levels. Spectroscopic measurements were performed in order to analyze the sources of combustion luminosity in a light-duty optical CI engine. A method has been described to distinguish between different sources of light. Based on this analysis, the following is concluded:
- Broadband chemiluminescence, a collective name for $\mathrm{CO}_{2}{ }^{*}, \mathrm{HCO}^{*}$ and $\mathrm{CH}_{2} \mathrm{O}^{*}$ chemiluminescence, dominates the spectrum for HCCI combustion. With increasing stratification, narrowband $\mathrm{OH}^{*}, \mathrm{CH}^{*}$ and $\mathrm{C}_{2}{ }^{*}$ chemiluminescence intensities increase.

- Whether the in-cylinder combustion can be analyzed by means of optical filters is questionable, since a significant broadband chemiluminescence signal is transmitted for both PPC and HCCI regimes.

- Broadband chemiluminescence can be used as a measure for the heat release rate. This implies that, as broadband emission and $\mathrm{OH}^{*}$ chemiluminescence correlate strongly with local rate of heat release, an $\mathrm{OH}^{*}$ bandpass filter can still be used since its signal will be proportional to the rate of heat release any way. However, further fundamental investigation and validation is required when different combustion parameters are used.

- Results show that there are two different chemical mechanisms for formation of $\mathrm{C}_{2}{ }^{*}$ in PPC regime: first during the early stage of combustion by the breakup of larger molecules and the second during the late stage of combustion when soot particles are forming.

- Atmospheric premixed laminar flames show that the $\mathrm{OH}^{*} / \mathrm{CH}^{*}$ ratio monotonically decreases with equivalence ratio. However, at elevated pressures an inverse relation is observed [28, this work]. This implies that the $\mathrm{OH}^{*} / \mathrm{CH}^{*}$ ratio can be used for equivalence ratio sensing, but only at certain pressures and temperatures. Thus, it is impossible to apply these relations in an IC engine with varying pressure. However, we indicated that the broadband chemiluminescence, particularly in the range of $330-400 \mathrm{~nm}$, does correlate with equivalence ratio quite well in both HCCI and PPC regimes.

Acknowledgements The research leading to these results has received funding from the People Programme (Marie Curie Actions) of the European Union's Seventh Framework Programme FP7/20072013/ under REA Grant Agreement No. 607214. The authors would like to acknowledge Shell Global Solutions for providing the Volvo D5 optical engine setup.

Open Access This article is distributed under the terms of the Creative Commons Attribution 4.0 International License (http://creativecommons.org/licenses/by/4.0/), which permits unrestricted use, distribution, and reproduction in any medium, provided you give appropriate credit to the original author(s) and the source, provide a link to the Creative Commons license, and indicate if changes were made.

\section{Appendix}

See Fig. 14. 

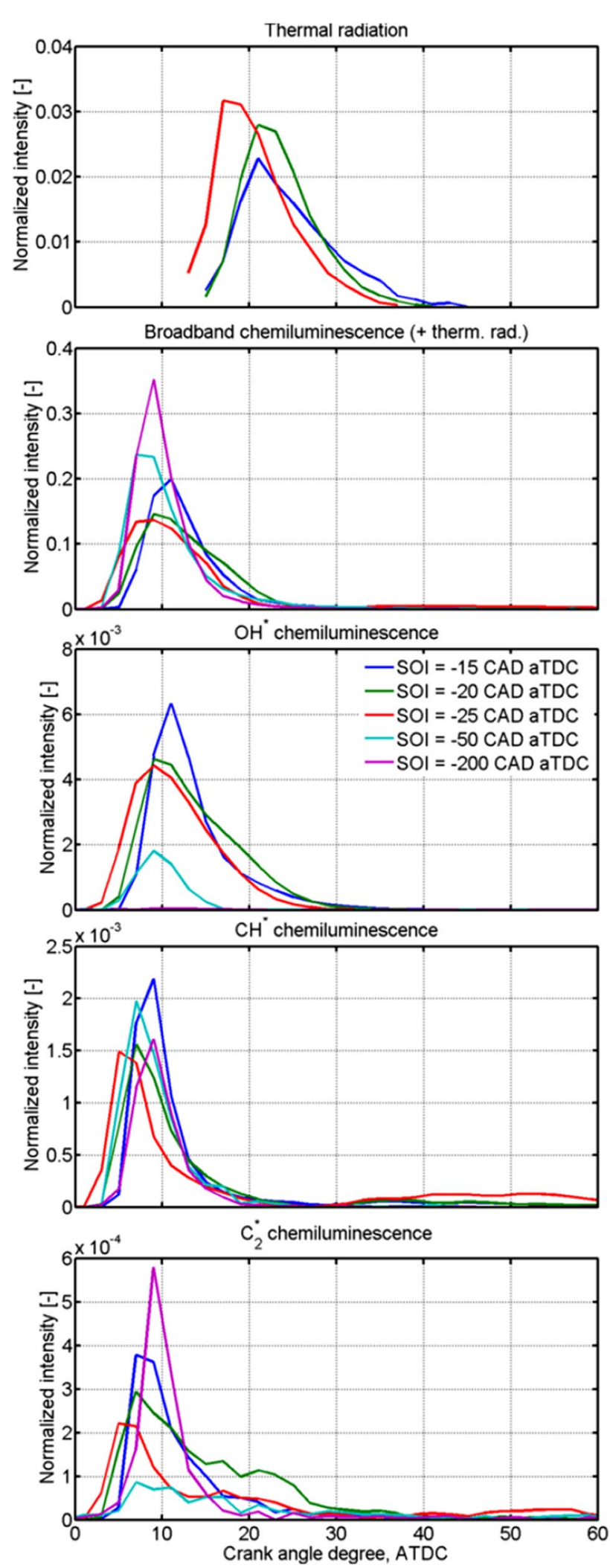

Fig. 14 Species chemiluminescence intensities for different injection timings based on two different normalization methods; left column Normalized by the total intensity of the combustion cycle to see the overall species behavior within a cycle $\left(\frac{\int^{s p} I_{s p}(\lambda, \mathrm{CA}) \mathrm{d} \lambda}{\int_{270}^{540} \mathrm{~d} \lambda \int_{-180}^{+180} I(\lambda, \mathrm{CA}) \mathrm{dCA}}\right)$. Right
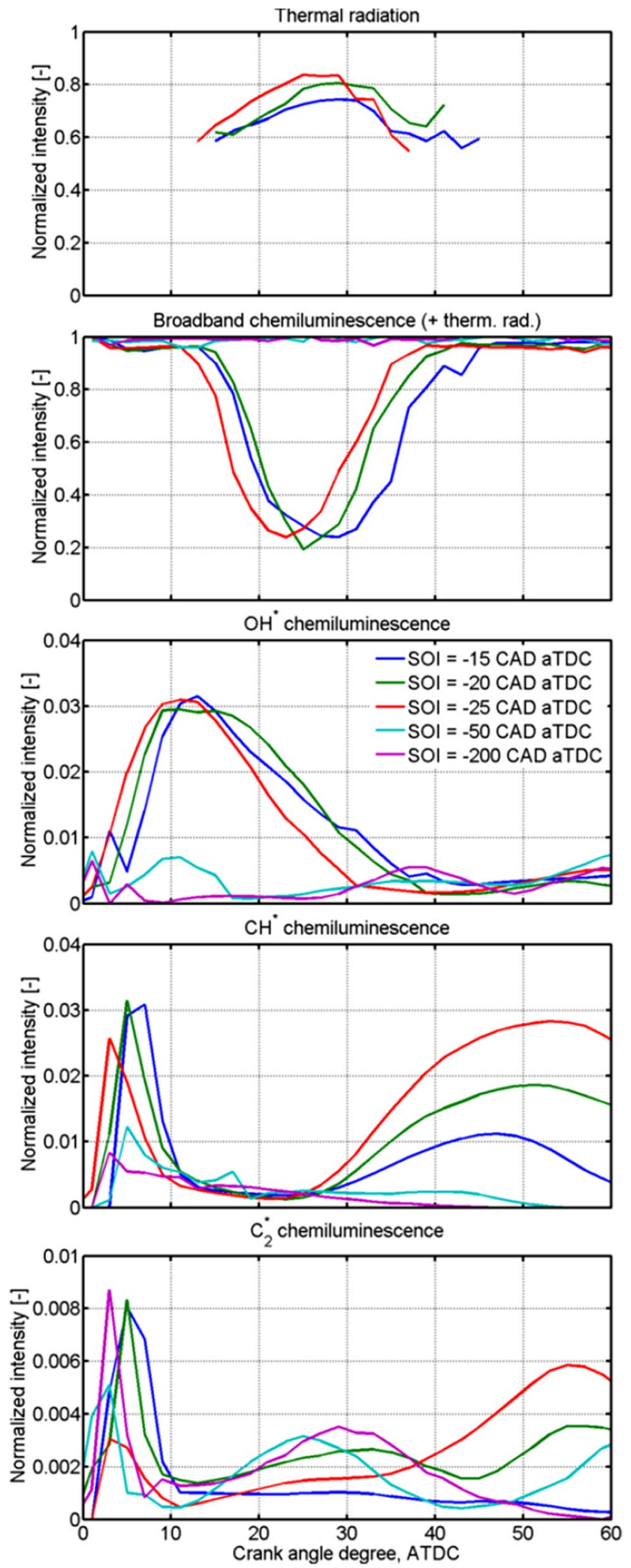

column Normalized by the total intensity at a given CAD (dynamic normalization) to see the role of each species at each CAD independently $\left(\frac{\int^{\mathrm{s}} I_{\mathrm{sp}}(\lambda, \mathrm{CA}) \mathrm{d} \lambda}{\int_{270}^{50} I(\lambda, \mathrm{CA}) \mathrm{d} \lambda}\right)$ 


\section{References}

1. L. Hildingsson, G. Kalghatgi, N. Tait, B. Johansson, A. Harrison, SAE Technical Paper 2009-01-2648 (2009)

2. M. Musculus, P. Miles, L. Pickett, Prog. Energy Combust. Sci 39, 246 (2013)

3. C. Noehre, M. Andersson, B. Johansson, A. Hultqvist, SAE Technical Paper 2006-01-3412 (2006)

4. M. Lewander, K. Ekholm, B. Johansson, P. Tunestål, N. Milovanovic, N. Keeler, T. Harcombe, P. Bergstrand, SAE Int. J. Fuels Lubr 1, 1063 (2009)

5. J.E. Dec, Proc. Combust. Inst 32, 2727 (2009)

6. R.D. Reitz, Combust. Flame, 160, 1 (2013)

7. M. Jakob, T. Hülser, A. Janssen, P. Adomeit, S. Pischinger, G. Grünefeld, Combust. Flame 159, 2516 (2012)

8. J. Dec, C. Espey, SAE Trans. 104, 853 (1995)

9. A. Hultqvist, M. Cristensen, B. Johansson, A. Franke, M. Richter, M. Aldén, SAE Technical Paper 1999-01-3680 (1999)

10. A. Gaydon, The Spectroscopy of Flames, (Springer, London, 1974)

11. J. Zhang, W. Jing, T. Fang, Fuel 99, 226 (2012)

12. T. Kathrotia, U. Riedel, A. Seipel, K. Moshammer, A. Brockhinke, Appl. Phys. B. 107, 571 (2012)

13. J. Dec, C. Espey, SAE Technical Paper 982685 (1998)

14. M. Kim, Y. Kaneko, T. Ikeda, Nakajima, Proc. Combust. Inst 29, 671 (2002)
15. R. Augusta, D. Foster, J. Ghandhi, J. Eng, P. Najt, SAE Technical Paper 2006-01-1520 (2006)

16. M. Izadi Najafabadi, N. Dam, B. Somers, B. Johansson, SAE Technical Paper 2016-01-0761 (2016)

17. S. Tanov, R. Collin, B. Johansson, M. Tuner, SAE Int. J. Engines 7, 1911 (2014)

18. J. Kojima, Y. Ikeda, T. Nakajima, Proc. Comb. Inst. 28, 1757 (2001)

19. Y. Hardalupas, M. Orain, Comb. Flame 139, 188 (2004)

20. F. Bowditch, SAE Technical Paper 610002 (1961)

21. K. Mollenhauer, H. Tschöke, Handbook of diesel engines (Springer-Verlag, Berlin, 2010)

22. G. Woschni, J. Fieger, SAE Technical Paper 790834 (1979)

23. J.A. Gatowski, E.N. Balles, K.M. Chun, F.E. Nelson, J.A. Ekchian, J.B. Heywood, SAE Technical Paper 841359, (1984)

24. M. Kopp, O. Mathieu, E. Petersen, Int. J. Chem. Kinet 47, 50 (2014)

25. V. Nori, J. Seitzmann, Proc. Comb. Inst 32, 895 (2009)

26. A. Yoshida, M. Narisawa, H. Tsuji, Symp. Int. Comb. 24, 519 (1992)

27. S. Merola, B. Vaglieco, F. Corcione, E. Mancaruso, SAE Technical Paper 2003-01-1112 (2003)

28. V. Nori, J. Seitzmann: AIAA 2008-953, (2008) 